\title{
ALGUMAS CONTRIBUIÇÕES DOS CONTOS DE FADAS NO DESENVOLVIMENTO INFANTIL
}

NOGUEIRA, Fabiana Aparecida ${ }^{1}$

COSTA, Sueli Silva Gorricho ${ }^{2}$

\begin{abstract}
RESUMO: Este trabalho tem como objetivo apresentar as características do Conto de Fadas tais como fantasia, conflitos existenciais, densidade, entre outros. Discutir a importância da literatura infantil no âmbito escolar, como as possíveis contribuições, suas implicações na infância, o desenvolvimento cognitivo e sócio afetivo da criança, polissemia. Dessa forma, esta pesquisa é fundamentada em teóricos que discutem e enfatizam a contribuição dos contos de fadas, bem como a criança em relação a ele e como a ela pode se desenvolver. Para isso a análise realizada contempla uma sala de $2^{\circ}$ ano do ensino fundamental 1, utilizando-se da coleta de dados por meio de contação de história e observação, 20 ilustrações, 19 desenhos feitos pelos alunos e o questionário respondido pela docente da sala, que são analisados posteriormente. Os resultados apontam que de fato os contos de fadas utilizados pedagogicamente em sala de aula podem contribuir de maneira significativa para o desenvolvimento dos alunos.
\end{abstract}

Palavras-Chave: Literatura infantil. Educação. Ludicidade. Autoria.

SUMMARY: This work have as goal to show the caracteristics of fairy tales, such as fantasy, existential conflicts, density and others. Discuss the importance of children's literature in the educational scope, like the possible contributions, your impications in the childhood, the cogntive development and the aspects social and affective, of a child, polysemy. In this way, this research is embase on theoretical that debate and lay emphasis in the contribution of Fairy Tales, Just like a child can evolve in relation of Fairy Tale. For this, the analysis accomplished includes a classroom of $2^{\circ}$ year of elementary school. Collecting data through of told stories and observation, 20 illustration, 19 drawings was made by the students and the questionnaire was answered by the instructor, that are analyzed later. The results show that the fairy tales can be utilized pedagogically in the classroom, contributing of a significant way to the progress of the students.

Keywords: Children's Literature. Education. Playfulness. Authorship.

\section{INTRODUÇÃO}

A partir da observação da prática de contação de história, na sala de aula pela pesquisadora, notouse que a literatura no ensino fundamental pode ser facilitadora no processo de ensino aprendizagem de maneira lúdica e prazerosa. Pode-se perceber que o modo de trabalhar, com intencionalidade pedagógica, pode estimular o desenvolvimento da criança, promover o raciocínio, despertar curiosidade e criatividade, favorecer a construção do conhecimento e oferecer uma forma concreta de aprendizagem aos alunos.

Os contos de fadas, há séculos, permearam o universo infantil com seus encantos e desencantos. Ainda nos dias de hoje continuam exercendo grande poder sobre as crianças, que por sua vez se identificam com os personagens e com a narrativa, devido à forte influência que possuem na abordagem de problemas existenciais. Os personagens não fogem aos problemas, há um enfrentamento com busca de soluções (mágicas) que sempre se encaminha para o final feliz. Ao entrarem em contato com os contos de

\footnotetext{
${ }^{1}$ Graduada em Pedagogia. Faculdade de Filosofia Ciências e Letras de Ituverava

${ }^{2}$ Professora Mestre da Faculdade de Filosofia Ciências e Letras de Ituverava, nos cursos de Letras e Pedagogia. Faculdade de Filosofia, Ciências e Letras de Ituverava
} 
fadas, seja por narração dos pais ou professores, ou mesmo por leitura própria, se abre para a criança um universo mágico capaz de transportá-la ao próprio mundo interior, onde são revividas emoções, conflitos e perdas. O que representa um apoio emocional, um consolo, uma esperança, oferecendo à criança simbolizar suas vivências e encontrar suas respostas. Os contos, como obra literária, são considerados obra de arte, e como todas as obras de arte, vão de encontro com os anseios de cada um, ou seja, as interpretações variam para cada pessoa, como também para a mesma pessoa em situações e tempos diferentes, pois as sabedorias das narrativas remetem à própria vida, o que faz com que continuem inabaláveis com a passagem do tempo.

Assim, buscou-se por meio desse trabalho levantar algumas questões em relação aos contos de fadas na educação de crianças, como as possíveis contribuições, suas implicações na infância, o desenvolvimento cognitivo e sócio afetivo da criança, a internalização de valores éticos, entre outros.

É muito importante para as crianças o contato com as narrativas dos contos de fadas, assim como, as ilustrações, que são partes indissociáveis da narração, excelentes recursos para fazer um paralelo entre a vida da criança e dos personagens, deixando que a imaginação flua, permitindo outras conquistas como o interesse pela leitura e o despertar para a autoria (leitura polissêmica).

Portanto, o trabalho consiste em um levantamento bibliográfico de obras críticas de escritores da literatura infantil, pedagogos e psicólogos, e de observação em sala de crianças do $2^{\circ}$ ano do ensino fundamental, análise de questionário da docente da sala de aula, desenhos e textos realizados pelos alunos com intuito de identificar o entendimento quanto à essência das histórias contadas, a interação com as narrativas e, a perspectiva das crianças em relação à própria vivência.

Pela pesquisa pode-se verificar a importância da literatura infantil no ambiente escolar com foco nos contos de fadas que é considerado um texto literário rico. Assim possibilita-se o acesso ao desenvolvimento cognitivo, afetivo social inserindo a criança em um universo semelhante a suas vivências com a exteriorização de conflitos e ao gosto pela leitura e a prática da escrita.

\title{
1 LITERATURA INFANTIL E OS CONTOS DE FADAS
}

\begin{abstract}
A Literatura não é cópia do real, nem puro exercício de linguagem, tampouco mera fantasia que se asilou dos sentidos do mundo e da história dos homens. Se tomada como uma maneira particular de compor o conhecimento, é necessário reconhecer que sua relação com o real é indireta. Ou seja, o plano da realidade pode ser apropriado e transgredido pelo plano do imaginário como uma instância concretamente formulada pela mediação dos signos verbais. (BRASIL, 1997, p. 37)
\end{abstract}

“A literatura é a mais importante das artes, pois sua matéria é a palavra, o pensamento, as ideias, a imaginação, - exatamente aquilo que distingue ou define a especificidade do humano". (COELHO, 1991, p.8). Assim, a literatura é um instrumento que agrega saberes e que contribui para a formação de leitores capazes de fazer uma interpretação não só do que lê, mas também do mundo a sua volta. E, também possibilitar as suas leituras e vivências às várias possibilidades de significado que cada palavra apresenta diante de cada situação.

A literatura infantil começou no século XVIII. Nessa época a criança começava, efetivamente, a ser vista como criança. Antes, ela participava da vida social adulta, inclusive usufruindo da sua literatura. As crianças da nobreza liam os grandes clássicos e as mais pobres liam lendas e contos folclóricos (literatura de cordel), muito populares na época. Como tudo evolui, esse tipo de literatura também evoluiu para atingir ao público infantojuvenil: os clássicos sofreram adaptações e os contos folclóricos serviram de 
inspiração para os contos de fadas. No Brasil a literatura infantil deu os primeiros passos com as obras de Carlos Jansen ("Contos seletos das mil e uma noites"), Figueiredo Pimentel ("Contos da Carochinha"), Coelho Neto, Olavo Bilac e Tales de Andrade. Porém, o mais importante escritor infantil foi Monteiro Lobato. É com ele que se inicia, de fato, a literatura infantil no Brasil. (GOMES, [s/d], n.p)

A importância da literatura infantil deve-se a sua especificidade, contribuindo de modo ímpar na formação integral da criança.

Por meio da literatura infantil e das narrativas dos contos de fadas, propriamente ditos, as crianças desenvolvem recursos internos ligados à imaginação, à cognição, o que a leva a sonhar, refletir e aprender. "A Literatura Infantil, enriquecendo a imaginação da criança, vai oferecer-lhe condições de liberação sadia, ensinando-lhes a libertar-se pelo espírito: levando-a a usar o raciocínio e a cultivar a liberdade". (CARVALHO, [19--], p-14).

Assim, Carvalho, ([19--], p-10), considera que "o conto infantil é uma chave mágica que abre as portas da inteligência e da sensibilidade da criança" e, completa: "o que fez de Andersen o grande escritor universal e imortal foram as estórias ouvidas quando criança".

A criança encontra nos contos uma forma de realização de seus desejos reprimidos, através do fantástico, do jogo livre da fantasia: desta maneira ela se realiza, superando as limitações que tem como criança, libertando-se. Ela realiza seu mundo interior, seu mundo impossível e utópico, na fantasia dos contos maravilhosos, onde tudo pode ser concretizado, mas se extraem de tudo símbolos de verdades eternas. (CARVALHO, ([19--], p.54).

Dessa forma, pode-se dizer que o conto de fada sempre esteve ligado ao sobrenatural e a autorrealização, ainda segundo Coelho (1991, p. 155), "os estudiosos acabaram por localizar as origens das fadas no contexto dos mitos, entendendo mito como expressão da experiência primordial do homem em relação ao mundo e à vida".

Os contos eram relacionados à vida cotidiana do homem, via a marcante relação dos sentimentos expressados por pessoas, de acordo com E. Cassirer (apud COELHO, 1991, p. 155):

A percepção mítica está sempre impregnada de qualidades emocionais, ações, forças e poderes conflitantes, cujo embate desses poderes é visto em todo fenômeno da natureza, de modo que o que é vivido está impregnado ou repleto de sentimentos como alegria, tristeza, angústia, excitação, exultação e depressão.

Ao observar os contos pode-se ver que na maioria das vezes eles possuem uma característica mística, vinda da imaginação das pessoas tendo como objeto de desejo a fada.

Para Coelho (1991, p. 155):

Se há personagem que apesar dos séculos e da mudança de costumes continua mantendo seu poder de atração sobre homens e crianças, essa é a fada". Pertencente à área dos mitos, a fada ocupa um lugar privilegiado na estrutura vital que neles é representada: encarna a possível realização dos sonhos ou ideais, inerentes à condição humana.

Por outro lado nem sempre nos contos de fadas existe realmente a figura da fada explícita, mas a história de alguma forma se relaciona a algo místico. "A magia não está no fato de haver uma fada já 
anunciada no título, mas na sua forma de ação, aparição, de comportamento, de abertura de portas...”. (ABRAMOVICH, 1994, p. 121).

Como diz Rodriguez (apud RIBEIRO, 2005, p. 56) os contos se difundiram na Idade Média com a proposta social de alertar e instruir as pessoas. "Os contos eram galhofas, que serviam para unir a comunidade, mas já com a função de educar: não saia da estrada, obedeça ao mais sábio, não ande sozinho à noite”. Já naquela época os contos cumpriam sua função social, devido à facilidade de identificação que sempre existiu entre as pessoas comuns e os personagens, por semelhanças de trajetórias e destinos.

Desse modo, pode-se observar que mesmo com o passar dos anos os contos possuem o mesmo traço da Idade Média. No mundo contemporâneo eles ainda continuam a cumprir o papel social visando de alguma forma trazer harmonia para a sociedade.

As narrativas maravilhosas decorrem no mundo da magia, da fantasia e do sonho, onde tudo escapa às limitações ou contingências precárias da vida humana e onde tudo se resolve por meios sobrenaturais, com elementos que povoam esse universo mágico que, desde os primórdios vem enchendo de beleza, poesia e sonho o espírito dos homens e das crianças. (COELHO, 1991, P. 154)

Os contos eram difundidos oralmente pelos adultos, nem sempre as crianças foram o foco dessa narrativa. As crianças eram vistas como adultas e o traço nos contos transmitidos não visavam à leitura delas.

"Os irmãos Grimm, Jacob e Wilhelm, levantaram dados e adaptaram as histórias contadas por camponeses, de forma inicial não para as crianças, apenas depois inseriram uma forma sensível, conservando a ingenuidade popular, a fantasia e o poético". (ABRAMOVICH, 1994, p. 123),

Com essa difusão dos contos de fadas por meio escrito, aos poucos foram transformados, adaptados, reescritos para a literatura infantil. De outra forma, pode-se notar que os contos de fadas foram ganhando amplitude.

Para Cashdan (2000 apud MATTAR, 2007, p. 14):

a grande contribuição para a popularização dos contos de fadas foi através do trabalho dos vendedores ambulantes pelos povoados de língua inglesa no século XIX, onde vendiam pequenos volumes com histórias simplificadas do folclore e dos contos de fadas, sem as passagens fortes, sendo de fácil leitura e baixo custo, considerado como a efetiva transformação dos contos em literatura infantil.

Assim, pode-se observar por meio dos autores que os contos de fadas passaram por grandes modificações até os dias de hoje, visto que eles, atualmente, são voltados ao universo infantil, devido ao lúdico; ao universo fantasioso, pela sua simbologia, como também pela presença de personagens arquétipos que inspiram as crianças nas realizações de suas fantasias e na resolução de seus conflitos.

Os contos de fadas podem ser contextualizados com o mundo da criança, pois de acordo com Abramovick (1994), "eles falam de medos, de amor, da dificuldade de ser criança, de carências, de autodescobertas, de perdas e buscas, favorecendo a criança as encontrar sentido nas narrativas dos contos". Dessa maneira as crianças se integram a eles facilmente, pois são na maioria das vezes os conflitos enfrentados por elas no dia a dia.

Sem tais conclusões encorajadoras, para Bettelheim (2013, p. 203), "a criança, após ouvir a história, acharia que de fato não há nenhuma esperança de se livrar dos desesperos de sua vida e que os contos fortalecem a criança para enfrentar os caprichos de sua vida". 
Portanto, percebe-se que os contos de fadas cumprem o papel social, faz com que as crianças alcancem seus desejos, pois se sentem fortalecidas a reconstruírem sua história de vida, por ter o conto como espelho.

A literatura infantil abre espaços para o desenvolvimento intelectual permitindo por meio da escrita, ilustração ou até mesmo a oralidade, que a criança expresse livremente seus anseios.

A importância dos contos de fadas se confirma por meio de sua permanência através dos tempos, segundo Abramovich, (1994, p. 121), "Os contos de fadas são tão ricos que têm sido fonte de estudo para psicanalistas, sociólogos, antropólogos, psicólogos, cada qual dando sua interpretação e se aprofundando no seu eixo de interesse", ou os contos de fadas não são utilizados apenas pelas crianças e sim em uma amplitude, esse fato se deve a possibilidade de abstração que eles proporcionam devido à simbologia das narrativas. No entanto, de certa forma ainda, para Abramovich (1994, p. 121), "a narrativa tem que assegurar que todos os elementos façam parte, as angústias, as facetas de crueldade, respeitando a integridade, a inteireza e a totalidade da narrativa".

Os conteúdos existenciais revelam que os contos de fadas possuem diversas facetas e, de acordo com Abramovich (1994), "falam de amor, da dificuldade de ser criança, de carências, de auto descobertas, perdas e buscas, questões fundamentais na vida humana". Por isso as crianças conseguem fantasiar, mas ao mesmo tempo inserir sua realidade.

Por meio dos contos de fadas e de textos literários de modo geral, é mostrado à criança uma possibilidade de lidar com a problemática existente em sua vida e enfrentá-la. A atemporalidade presente nos contos assim como a identificação das crianças com os personagens e situações da narrativa colabora para que ela elabore com sucesso os conflitos e os domine. Pois as mensagens tranquilizadoras presentes nos contos fornecem recursos para significar e dar sentido a vida.

\section{METODOLOGIA E PROCEDIMENTOS}

\subsection{Metodologia}

A pesquisa foi realizada em uma instituição particular da rede de ensino de uma cidade do interior paulista, que atende alunos do $1^{\circ}$ ano do ensino fundamental ao $3^{\circ}$ ano do ensino médio. O público escolhido para a realização da pesquisa foi uma sala de aula com 20 alunos, do $2^{\circ}$ ano, do Ensino Fundamental, na faixa etária de 7 anos, sendo 10 meninas e 10 meninos.

A pesquisa teve duração entre as datas 04 a 25 de março de 2015 com intuito de investigar a contribuição dos contos de fadas na educação de crianças, suas implicações na infância e o desenvolvimento cognitivo e sócio afetivo da criança.

Para identificação e a preservação das identidades dos alunos utiliza-se de números de 1 a 6 .

A investigação utiliza como metodologia o levantamento bibliográfico e pesquisa de campo, de cunho qualitativo, com a intenção de exprimir as implicações do conto de fadas.

O procedimento para coleta de dados e posteriormente análise, deu por meio da observação, realização de atividades e questionário com a professora.

\subsection{Procedimentos}

No primeiro momento, 4 de março de 2015, a pesquisadora foi à instituição de ensino e entrou em contato com a diretora, explicou o objetivo do trabalho e suas possibilidades de realização. Houve grande 
envolvimento por parte da diretora que se mostrou solícita oferecendo o espaço físico da escola, prontificando-se a auxiliar no que fosse preciso e disponibilizando-se a entrar em contato com a professora regente da sala de aula para verificar a possibilidade da execução da pesquisa.

A escolha da sala do $2^{\circ}$ ano do Ensino Fundamental, a única existente na instituição, foi devido às características buscadas pela pesquisadora, a ludicidade e a capacidade de escrita, ao mesmo tempo. A professora da sala, participante, é da área de língua portuguesa e exerce a profissão de PEB I há vinte cinco anos, nesta instituição há 18 anos.

Após esse primeiro contato houve a apresentação do termo de responsabilidade que foi autorizado e assinado pela diretora e pela professora, na qual agendou-se uma conversa e apresentou-se a proposta, a pesquisa de campo com as crianças, a leitura e/ou a contação, para posteriormente realizar a pesquisa.

No segundo momento, 06/03/2015 a pesquisadora foi apresentada à professora pela diretora na sala de professores. Em uma conversa inicial, mostrou-se o objetivo do trabalho e pesquisa esclarecendo o tempo a serem realizado, negociado os dias e as horas disponíveis. Em seguida realizou-se uma avaliação diagnóstica com a professora sobre o desenvolvimento dos alunos e o questionário, para ser respondido, com objetivo de conhecer o trabalho e a prática pedagógica docente. Foi observado grande interesse por parte da professora em colaborar com a pesquisa, se mostrando entusiasmada com o tema devido a grande relevância do mesmo.

Foram feitas cinco perguntas específicas à professora regente a respeito dos contos de fadas:

1) Há quanto tempo exerce a função de professora?

2) Utiliza os contos de fadas na prática docente?-Se sim, por quê? Qual a frequência?

3) Qual sua opinião em relação às implicações dos contos de fadas para as crianças?

4) O que pode ser observado no comportamento ou as vivências das crianças em relação aos contos de fadas?

5) Qual a relação dos contos com o desenvolvimento cognitivo e sócio afetivo da criança?

Na primeira questão, busca descobrir a quanto tempo ela exerce a função de professora, e assim, verificou-se que ela trabalha há vinte cinco anos como PEB I (Professor de Educação Básica I - $1^{\mathrm{a}}$ ao $5^{\mathrm{a}}$ ano do Ensino Fundamental).

Na segunda questão, verifica-se que a docente uttiliza os contos de fadas na prática docente com a frequência de pelo menos uma vez por semana, "por ser uma história fora de espaços físico e temporal determinado, dá a criança a liberdade de criar, imaginar permitindo ao professsor diagnosticar como a criança se sente diante do mundo".

Com base na análise dessa questão, pode-se notar que mesmo que a escola passe pela obrigatoriedade de cumprir prazos e rigorosamente apostilas, testão (prova contendo questões referentes aos conteúdos desenvolvidos em todas as disciplinas), é possível trazer para os ambientes escolares momentos que permitem o contato da criança com a literatura desenvolvendo seu potencial criativo, suas reflexões de mundo e contribuindo para seu desenvolvimento social, afetivo e cognitivo.

$\mathrm{Na}$ terceira questão, perguntou-se sobre a sua opnião em relação as implicações dos contos de fadas para as crianças, segundo ela "as implicações dos contos de fadas para as crianças está no fato de que esta atividade é uma das mais antigas do homem. Sendo assim, saber ouvir e contar histórias desperta a curiosidade, a fala, exposição de ideiais e a transferência de conheciments entre outras", o que vai de acordo com Carvalho ([19--], p. 10) “o conto infantil é uma chave mágica que abre as portas da inteligência e da sensibilidade da criança, para sua formação integral". 
Na quarta questão, busca-se saber da professora qual o comportamento ou as vivências em relação aos contos de fadas, para ela "as crianças atuais não vivenciam em seu cotidiano os contos de fadas, pois a sociedade vigente não valoriza os valores morais presentes neste tipo de leitura”. Por outro lado, pode-se observar que a família também teme por estimular a fantasia nas crianças a ponto delas viverem em mundo irreal e fantasioso, segundo Bettelheim (2013, p. 169), "outros pais temem que a mente de uma criança possa ficar tão saturada de fantasias de conto de fadas a ponto de não se preocupar em aprender a lidar com a realidade".

Na quinta questão, o objetivo era investigar qual a relação dos contos com o desenvolvimento cognitivo e sócio afetivo da criança, para a docente, assim, ela respondeu que "esse contato deve ser iniciado com os familiares, pois pela voz do pai ou da mãe as crianças começam a experimentar: emoções, gestos, imitações, fantasias, imaginações e neste momento de "leitura" a criança irá se desenvolver e ter mais intimidade com familiares e outras.

Segundo Lajolo (1986, p. 43):

É a literatura porta de um mundo autônomo que, nascendo com ela, não se desfaz na última página do livro, no último verso do poema, na última página do livro, na última fala da representação. Permanece ricocheantando no leitor, incorporado como vivência, erigindo-se em morco do percurso de leitura de cada um.

Ao analisar a resposta da professora referente a esse questionamento, pode-se observar que esse contato primordial é essencialmente importante, mas mesmo que a criança não tenha tido esse contato com a literatura, por meio da família, cabe à escola inseri-la no mundo literário, pois independente da idade será uma experiência enriquecedora para a criança, desde que a semente seja plantada. Portanto pode-se observar por meio dos questionamentos que a professora possui um papel fundamental no desenvolvimento do aluno leitor, mesmo que seja negligenciada à criança, o acesso ao texto literário de qualidade, cabe ao professor oferecer várias possibilidades desse contato entre aluno, texto e leitor.

No terceiro momento, 11/03/2015 a pesquisadora foi apresentada aos alunos como uma estudante de pedagogia, que está fazendo um trabalho e que os alunos da classe irão participar, permanecendo na sala para observação buscando compreender o funcionamento, a realidade local, a motivação, o comportamento e a interação com a professora, assim como a intervenção da mesma e a desenvoltura dos alunos diante das atividades propostas. Observou-se que a sala é praticamente homogênea e que a maioria dos alunos possui comprometimento e interesse. A professora tem domínio sobre a sala, consegue atrair a atenção por meio de metodologias diferenciadas e em consequência disso o comportamento dos alunos é considerado satisfatório.

No quarto momento, 13/03/2015 a pesquisadora colaborou como auxiliar na sala de aula durante a aplicação de atividades diversas com a intenção de promover uma interação com as crianças e o intuito de gerar uma familiarização. Observou-se que as crianças estão alfabetizadas, pedem ajuda para escrever quando surgem dúvidas de ortografia e para escrever palavras desconhecidas. A professora é muito atenta revistando os cadernos o tempo todo, em cada carteira e, aproveitando para ensinar e corrigir os erros individualmente.

No quinto momento, 18/03/2015 a pesquisadora apresentou-se aos alunos, explicando por qual motivo estava presente; e que necessitaria da ajuda deles para o desenvolvimento do trabalho. As crianças se mostraram entusiasmadas e à vontade.

Foi essencial a conduta da professora, que permaneceu na sala dando toda liberdade para a execução da atividade, que foi muito produtiva devido ao envolvimento e interação dos alunos. 
Para a realização da atividade escolheu-se a narrativa $O$ Patinho Feio, de Hans Christian Andersen, no entanto a sua obra é de difícil classificação enquanto gênero, há autores que consideram como uma fábula moderna outros como conto..., "pois todos os gêneros são encontrados em Andersen, enriquecidos de beleza e fantasia inimitáveis... a sua experiência é vivida e sentida". (CARVALHO, [19-], p.196).

Dessa forma buscou levar para as crianças uma literatura onde elas fossem capazes de se identificar, trazer uma significação, busca, satisfação pessoal e resolução dos conflitos internos, ainda segundo Carvalho ([19--], p. 97):

Literatura como toda arte, é uma necessidade superior, e por vezes, inconsciente, de
buscar soluções ou de libertar-se, através de um esforço interior: resultado do conflito
que se processa no inconsciente ou de uma busca de satisfação. Então a teoria
psicanalítica aí está, provando que a criação artística é expressão da vida emocional do
homem: na literatura Infantil, o lindo conto-fábula "O Patinho Feio", de Andersen, é um
comovente exemplo. Loeffler-Delachaux parece-nos conciliar a explicação das fontes
primitivas com as interpretações psicanalíticas preconizadas por Freud, onde o homem
se refugia de suas inseguranças e limitações, diante das forças da Natureza, buscando a
satisfação psicológica na fantasia. Assim, também a criança encontra nos contos uma
forma de realização e libertação.

Na primeira abordagem sobre a história a pesquisadora questionou os alunos, se conheciam a história O Patinho Feio, de Hans Christian Andersen e se gostavam, a maioria respondeu que conhecia e gostava.

Ao realizar a leitura, a entonação da voz era alterada como, por exemplo, na frase: "a mulher saiu dando vassourada no patinho feio", onde a expressão era de autoritarismo: Vai Patinho Feio, SAI, SAI, SAI!!!, como também, na frase sobre o lago, a entonação é de encantamento. Foi observado o comportamento das crianças quanto à entonação, pois permitia que elas também se expressassem e entrassem na história, participando com emoção.

Durante a leitura permitiu-se que as crianças acompanhassem a narrativa por meio das ilustrações do livro, ou seja, toda parte lida era embasada com a respectiva ilustração. Foram admitidas pequenas interrupções onde os alunos sentiram-se livres para questionarem ou comentarem sobre a narrativa.

O comportamento dos alunos demonstrou interesse e curiosidade, pois pediam para aproximar o livro e se deslumbravam com as ilustrações, sendo que alguns colocavam a mão sobre a folha do livro para verificar a ilustração. Já na parte da leitura onde descreve a rejeição sofrida pelo patinho, a princípio pelo próprio pai e em seguida pelas pessoas que o viam durante o passeio, além da curiosidade quanto à ilustração foi observado o fascínio pela narrativa que foi comentada pelos alunos que exclamaram: "Já sei, então o patinho sofria bullying!”, seguido por “Ai que dó do patinho!” e “Ele é muito feio!”.

Posteriormente à leitura foi proposta uma atividade de ilustração onde foi concedido ao aluno expressar sua vivência diária de acordo com a narrativa e sua expectativa. Mesmo sendo uma história conhecida pelos alunos, eles se mostraram entusiasmados e interessados, o que colaborou para um bom andamento da atividade.

No sexto momento, 20/03/2015 realizou-se a contação da história, O Patinho Feio - Hans Christian Andersen. Ao contar a história as crianças interrompiam e participavam da construção e de seu percurso, enriquecendo e ao mesmo tempo dando consistência e veracidade aos momentos da narrativa. Em seguida espontaneamente algumas crianças, da sala de aula, de forma individual, contaram parte da história que gostaram, ou seja, que dizia algo para eles, segundo a experiência própria de cada um, com suas expectativas, buscas, anseios e esperanças. 
$\mathrm{Na}$ contação da história, a pesquisadora se posicionou em pé um pouco a frente da sala, movimentando-se quando necessário e após isso foi retomada a narrativa tendo o livro à mão, e à medida que se contava foi apresentado novamente às ilustrações de acordo com a sequência do conto. Isso foi feito na intenção de instigar as crianças a produzirem um texto autoral.

No sétimo momento, 25/03/2015 foi retomada a história relembrando e enfatizando todo seu universo de ações, acontecimento e situações da narrativa, levando as crianças a se inteirarem do contexto para serem capazes de uma interpretação textual polissêmica e uma produção autoral.

Nesse momento, a pesquisadora perguntou para as crianças se lembravam, gostaram e se entenderam a história do Patinho Feio. Em seguida as crianças foram orientadas a pensar na história e entender os acontecimentos deixando às vezes que elas continuassem o pensamento. Com a imaginação fluindo abre-se espaço por meio da identificação com os personagens, a outras vozes onde a criança se coloca diretamente naquela vivência, propiciando a autoria.

A partir desse momento as crianças são levadas a escrever um texto que seja significativo para elas, pois elas já se identificaram e conseguiram elencar momentos densos e conflituosos característicos de um conto de fadas na sua vida. Assim como o patinho feio passa por momentos difíceis, de dor, desprezo, indiferença e maus tratos, a criança também precisa resgatar a esperança para se chegar ao final feliz, ou seja, a resolução dos conflitos. Na vida da criança também existem situações onde ela se sente igual ou com os mesmos problemas que o Patinho Feio. Portanto, há uma identificação por meio de simbolização com a problemática envolvida.

Para o desenvolvimento da atividade, foram entregues folhas de papel em branco para as crianças para que elas escrevessem uma história, lembrando que cada uma escrevesse um texto do seu jeito, de acordo com o que entendeu e gostou, instigando a não produzirem uma mera repetição, pois a história do Patinho Feio já tem seu autor, como foi visto se chama Hans Christian Andersen. A pesquisadora enfatizou que escrevessem uma história contada por eles mesmos, na qual cada um seria o autor, deixando claro que as histórias ficariam diferentes umas das outras.

Esse momento foi de perguntas, indagações e dúvidas e algumas crianças questionaram como fazer. A pesquisadora ajudou-as no sentido de lembrar passagens da história que gostaram voltadas mais para um enfoque ético do que temporal, ou seja, não enfatizando passagens corriqueiras do dia a dia simplesmente e, sim utilizando essas passagens para alertar sobre a problemática da história, com a sua densidade e conflitos. Em seguida foi realizada pelas crianças a construção de um texto. A postura da pesquisadora nesse momento foi apenas de conduzir a construção textual de modo a dar total liberdade de expressão.

\section{ANÁLISE E DISCUSSÃO DOS RESULTADOS}

\subsection{Análise}

Dos vinte desenhos apresentados três chamaram atenção da pesquisadora por conter características relacionadas aos contos de fadas, ou seja, a densidade e a busca por integração.

Na figura 1, pode observar impressões marcantes pelo aluno 1 em suas interpretações em forma de ilustrações, pois ele realmente desenhou o patinho feio como um ser diferente e destoante do grupo, o que vai de encontro com seu comentário a respeito do patinho sofrer bullying. 


\section{Os desenhos}

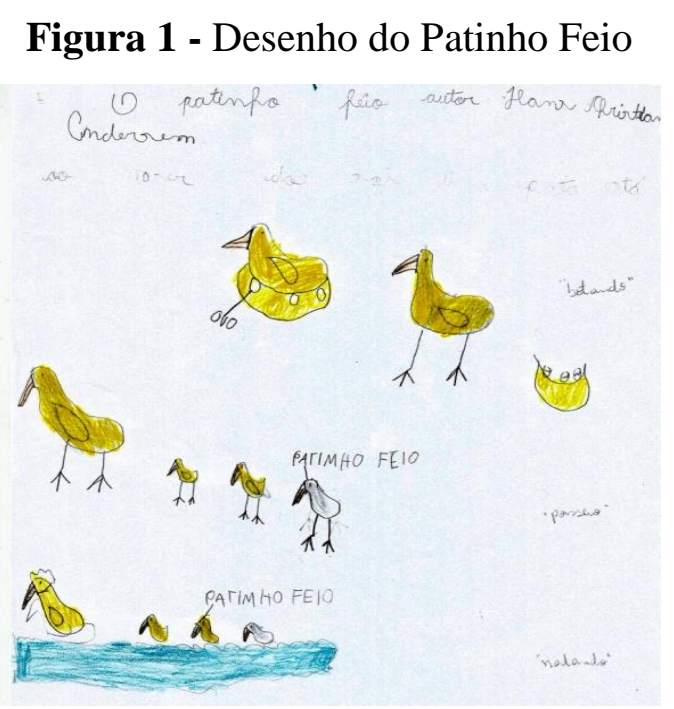

Fonte: Arquivo Pessoal

O aluno 1, descreve situações desde o nascimento demonstrando a falta de integração ao grupo devido a diferença física onde todos os patinhos são amarelos e o patinho feio é cinza. Na figura ilustrada observa-se a fisionomia triste do patinho feio em relação à ninhada, durante o passeio nadando no lago e também por ser colocado em último lugar na fila.

Observe a figura 2 abaixo:

Figura 2: O desprezo do Patinho Feio

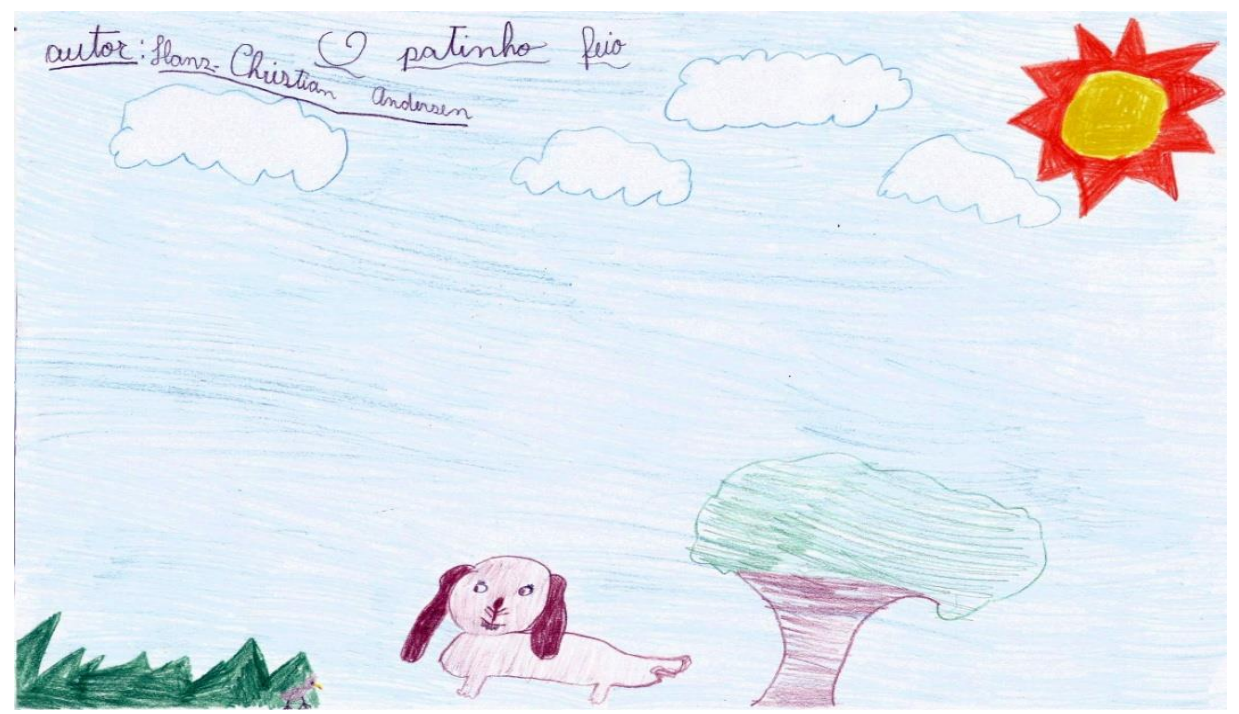

Fonte: Arquivo Pessoal

Na figura 2, observou o nítido desprezo que o Patinho Feio sofria, pois ilustrou claramente a ferocidade de um cachorro mostrando seus dentes afiados como mostra na história, ignorando o pobre do patinho, que sentiu realmente a situação. Foi representada no desenho a insignificância do Patinho perante o cachorro, sendo este desenhado de um tamanho muito maior do que aquele. Em relação ao ambiente nota-se também que tudo é muito maior do que o patinho que se encontra quase invisível entre as 
folhagens. A paisagem é exuberante criando um contraste perceptível com a quase inexistência do patinho. Mostrando a falta de integração e pertencimento do personagem.

Figura 3: Final feliz

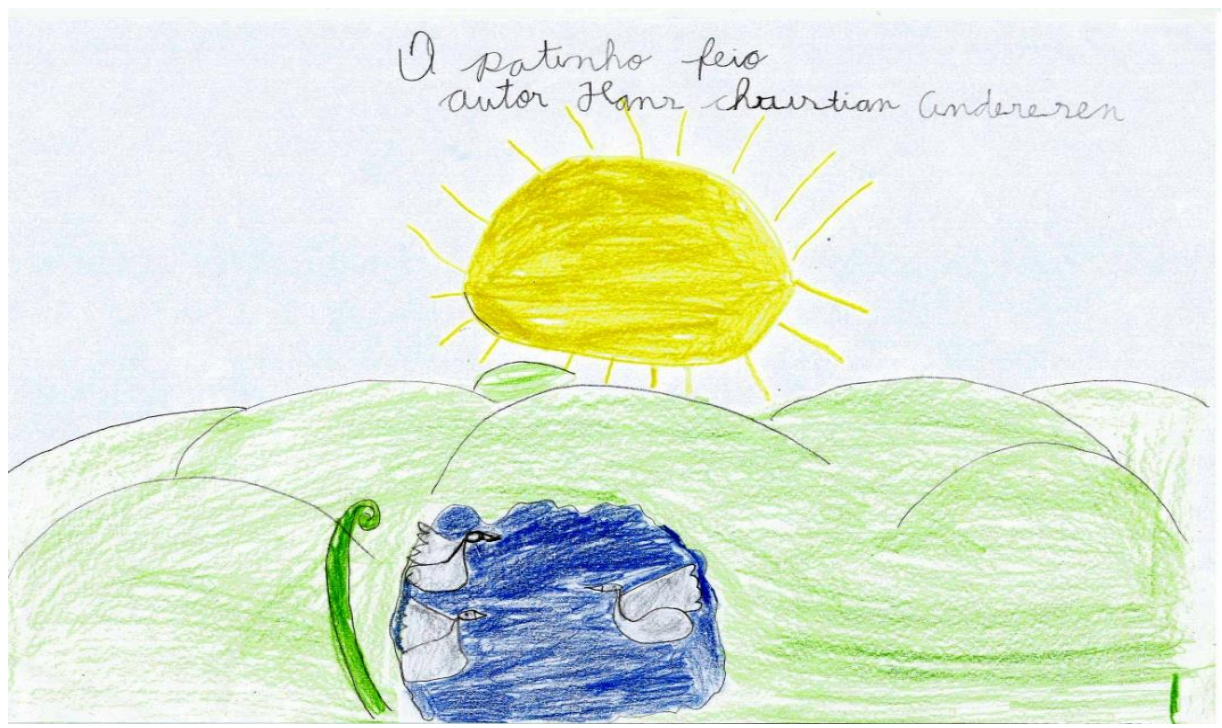

Fonte: Arquivo Pessoal

Na figura 3, o aluno 3 ilustrou a parte final do conto. Ele foi capaz de retratar a áurea de harmonia referente ao final feliz do patinho. Que após todo seu sofrimento e busca incansável por integração, pertencimento e busca pela identidade finalmente encontra seus pares, ou seja, seus iguais e sua família mostrando na ilustração um clima pacífico onde até a natureza retratada de forma suave e equilibrada conspira para a felicidade do personagem, em um consenso com a natureza, pois segundo Abramovich (1994, p.135), "O poder de se encontrar, se conhecer, depois de ter sido patinho feio, que só percebe cisne após descobrir sua identidade, o que significa percorrer uma trajetória longa, difícil e muita sofrida... Aí a belezura é total!!!”.

\section{$\underline{\text { Os textos }}$}

No segundo momento a partir de 19 textos, pois um aluno faltou, foi escolhido aletoriamente 3 textos que são analisados e apresentados a seguir: 
Texto 1: O menino com vergonha

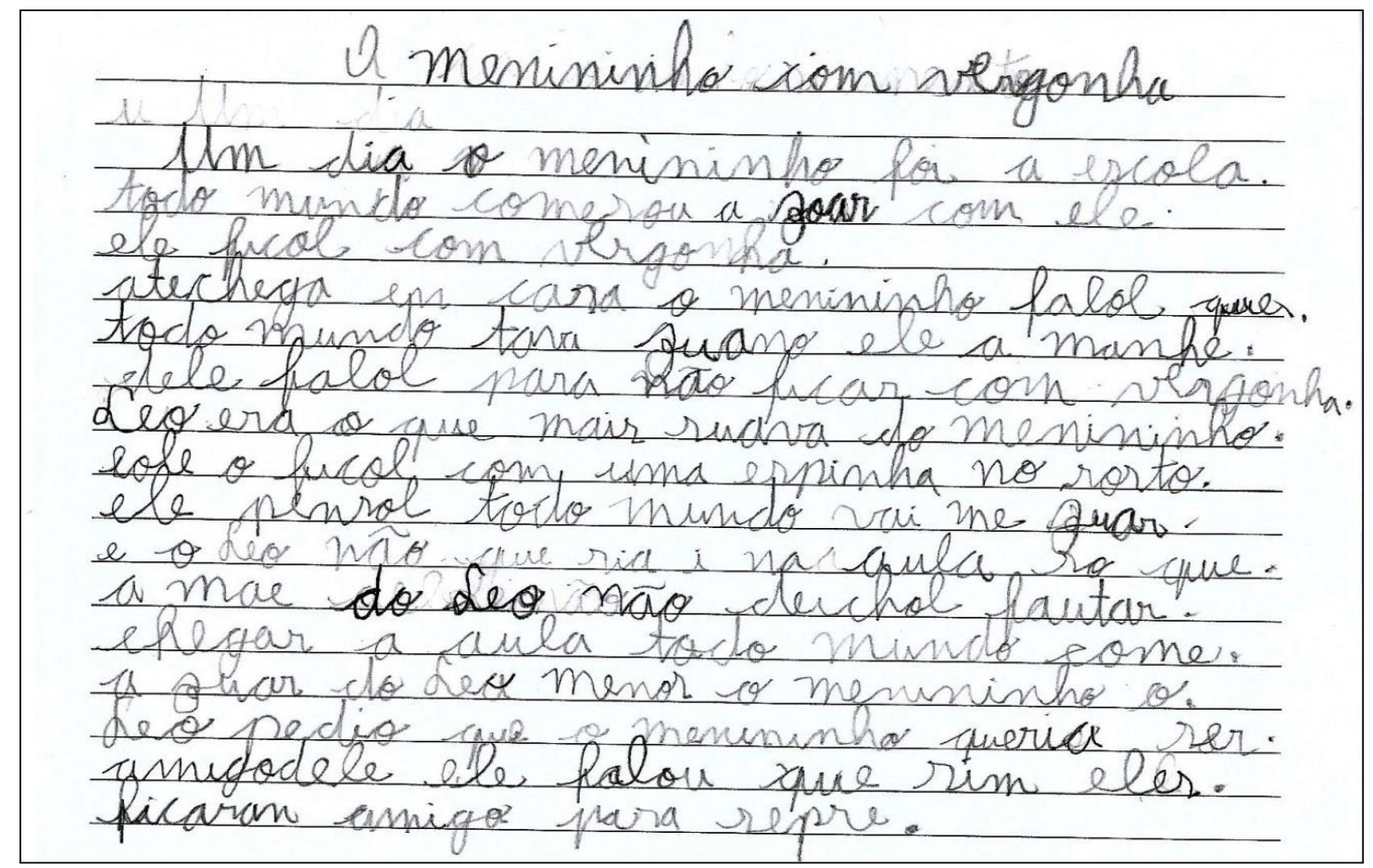

Fonte: Arquivo Pessoal

Na história original do Patinho ele é rejeitado, sofre abandono e injustiças por todos inclusive pela sua própria família, já na história do aluno 4 (texto 1) ele é acolhido e instruído pela sua mãe a não se sentir mal diante de uma situação de rejeição o que colaborou para uma aproximação com o colega.

Observe o texto 2:

Texto 2: O ovo da mamãe passarinha e dos cisnes

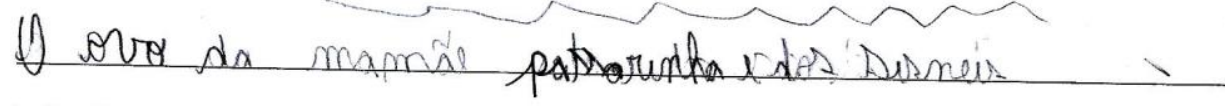

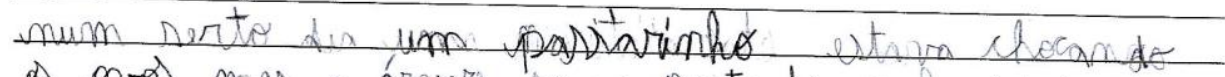

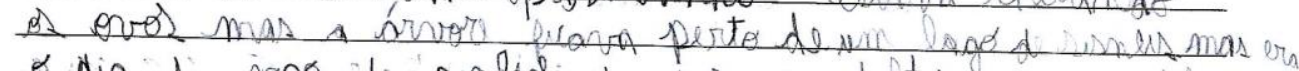

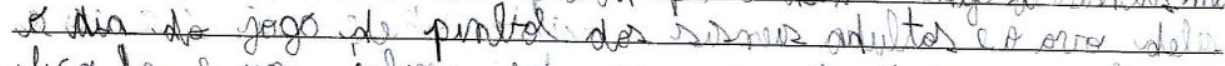

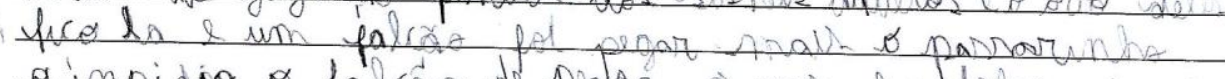

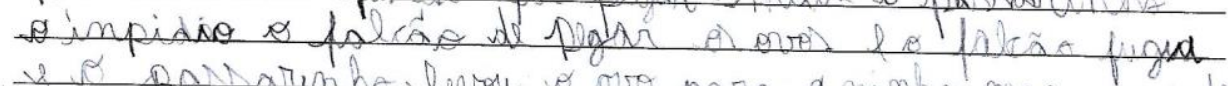

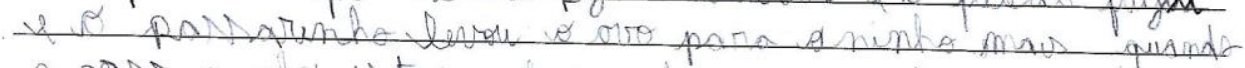

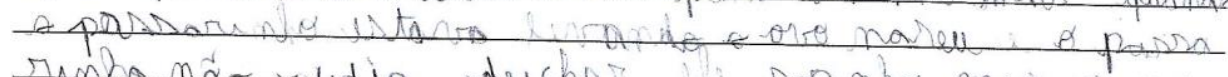

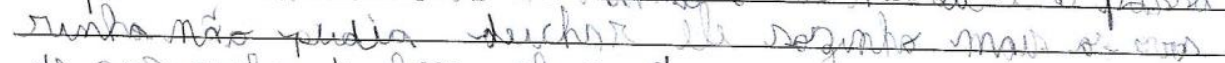

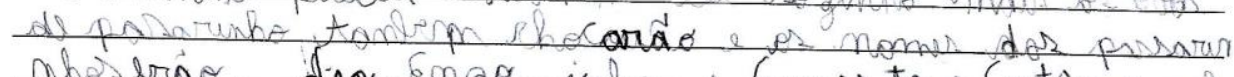

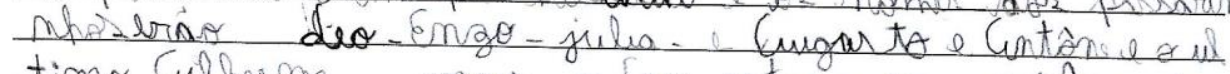

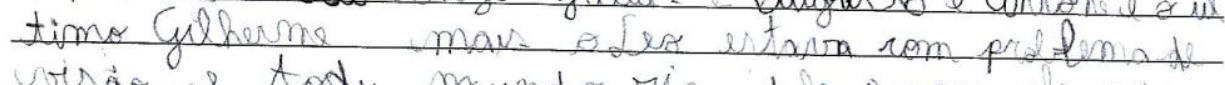

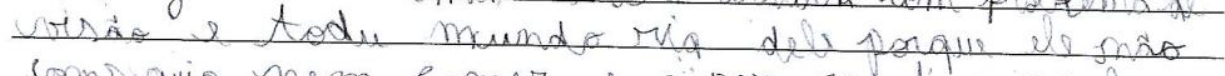
coms quia nem exmer e a papara dise que de pro

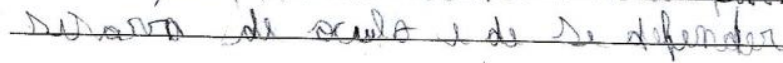


No texto 2, do aluno 5, verificou-se que também houve inserção de novos elementos como na frase "o passarinho disse que ele precisava de óculos e de se defender", pois a solução veio por meio do passarinho, o instruindo a se defender de todos que riam dele devido ao problema de visão que ele tinha que até o atrapalhava na hora de comer.

Observe o texto 3 selecionado:

Texto 3: O Gordinho Feio

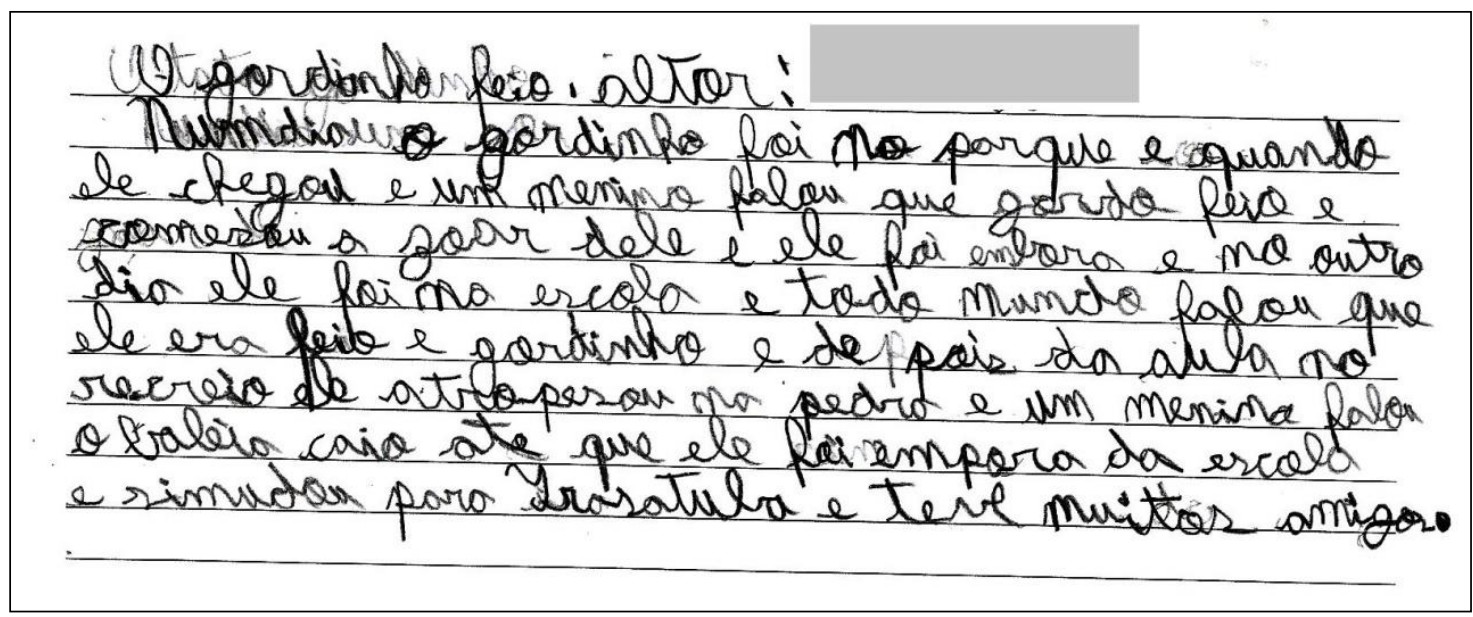

Fonte: Arquivo Pessoal

Nota-se o drama descrito pelo aluno 6 vivido pelo gordinho feio, a opressão e a perseguição sofrida em sala de aula e por fim o alívio, a aceitação.

\subsection{Resultados}

Como um bom conto de fadas o Patinho Feio foi capaz de despertar nas crianças, visto por meio dos desenhos, a repetição da figura do patinho destoando dos demais por ser diferente e considerado feio, não inserindo no contexto social dos demais, por sendo sempre alvo de desprezo e indiferença inclusive do pai. Alguns conseguiram distinguir momentos importantes da narrativa utilizando cores e traços adequados a sua percepção. Porém, a maioria das crianças se ateve ao final feliz confirmado por meio de muitas ilustrações do encontro do patinho com os cisnes na lagoa, em uma atmosfera de harmonia, paz e plenitude, em que até a natureza ao redor conspira.

$\mathrm{Na}$ análise dos textos percebe-se que as crianças obtiveram condições internas de resolução de conflitos que supostamente existiam, pois é como se houvesse uma divergência que precisasse ser resolvida ao invés de fugir, buscaram uma solução, ficando um clima acolhedor e tranquilo no ambiente de convívio. De acordo com Bettelheim (2013), "foi visto claramente que o conto sempre sugere que os conflitos possam ser solucionados, pois fornecem meios para atingir a sublimação". Vale ressaltar que os alunos 4 e 5 souberam utilizar a densidade do conteúdo transpondo para sua vivência.

Portanto, ao analisar o texto do aluno 4 e 5 pode-se notar que eles deixaram de ser um mero reprodutor de conhecimentos e conseguiram escrever um texto fora do esperado. Dessa forma nos permite afirmar que foram capazes de fazer uma leitura polissêmica, pois somente por meio dela é possível “... instalar novos sentidos, deslocando o aluno do lugar de mero receptor de conteúdos e sentidos já legitimados e sinalizando para ele a possibilidade de expressão, questionamentos, polêmica e dúvidas." (ROMÃO; PACÍFICO, 2006, p. 60).

No texto 3, O gordinho feio, a fala do aluno vem de encontro à fala de Abramovich (1994, p. 135): 
Nos falam da dificuldade de ser criança ou jovem, de como é preciso provar nossa capacidade a cada instante, de como temos que nos afirmar como pessoa - o que acontecerá quando nossa própria identidade, tiver sido alcançada, após um longo período de buscas, de sofrimentos, de rejeições... E de como todas essas turbulências internas que fazem parte da condição humana - também podem ser compreendidas ou resolvidas através do encantamento, da magia, da presença do maravilhoso... Falam de pessoas e de suas buscas de felicidade.

Vale ressaltar que são comuns as dificuldades encontradas por crianças no seu dia a dia onde sentem incompreendidas, perseguidas e por isso infelizes. As histórias de forma geral ajudam a criança à transcender esses momentos dando-lhes elementos para a busca de uma solução.

Assim, Romão; Pacífico (2006), "Manuel Bandeira ao imaginar Passárgada como um local ideal pra se viver", não podemos deixar de comparar a Trasatuba do aluno 6 com a lendária Passárgada de Manuel Bandeira, para Lajolo (1986, p.46), "a própria criação da utopia se nutre sempre de uma imaginação ancorada na realidade". Dessa forma, pode-se analisar que as duas situações remetem a fuga para um local imaginário onde todos os problemas seriam solucionados, não existindo as dores e conflitos. Segundo Bettelheim (2013), “As histórias criadas pelas crianças são expressões próprias de suas angústias e surgem em decorrências de suas vivências", onde por vezes concretizam dando nomes próprios aos locais que imaginam, como a expressão Trasatuba criada pelo aluno 6 na sua ânsia de resolver um conflito.

Outra passagem que se pode analisar, são os traços destacados pelo aluno 6 ao se denominar criador da própria história intitulada $\mathrm{O}$ gordinho feio, pode-se dizer que o aluno foi capaz de relatar seu contexto social na história. Na vida do autor Andersen ele escolheu para expressar suas angústias sofridas em seus personagens animais, segundo Carvalho ([19--], p. 193):

Há mesmo, em Andersen, estórias autobiográficas, como a do "Patinho Feio". Andersen se faz representar pelo Patinho, que, desprezando em seu meio, algumas vezes pela própria mãe, que não chegou a entende-lo inteiramente, teve que fugir para longe, reconhecessem o seu valor, porque entre os galináceos ele não passava de um tolo e estranho bípede emplumado. O "Patinho" é a sua vida, durante os anos de escola, a longa caminhada que foi "um longo suplício", quando ele se preparava para transformar-se no belo "cisne". E, só no grande lago dos cisnes, ele é reconhecido como tal.

Por isso, pode-se analisar que o aluno utilizou a escrita como uma forma de expressar suas angústias passadas no dia a dia inseridas no texto, de acordo com Bettelheim (2013, p.173), "Todas as histórias que ela pode inventar são apenas expressões de seus próprios desejos e angústias".

Verifica-se, então, que ao interagir com as histórias as crianças dão vozes aos seus sentimentos mais profundos, sendo capazes de se situarem, concretizando-os e elaborando-os.

Em relação aos demais desenhos e textos não apresentados verificou-se que os alunos mostraram, em âmbitos gerais, uma maior tendência para imitar ou copiar os elementos apresentados como solução na narrativa do O Patinho Feio, pois a maioria escreveu histórias em que o personagem precisa fugir do local do conflito para encontrar a paz, se sentir integrado com sentimento de pertencimento, ser feliz e realizado. Entretanto, foram apresentados textos polissêmicos com a inserção de elementos novos, como também textos mostrando a resolução do conflito e a busca de solução no local.

Dessa forma, com base no texto literário O Patinho Feio, pode-se observar que esse tipo de texto presente no dia a dia como forma de conhecimento do aluno proporciona inúmeras contribuições; motivando-os a outros modos de se ver a vida, resolver conflitos, instigar a leitura diária, estimular a imaginação, formação de escritores e leitores autônomos e faz com que eles se desenvolvam intelectualmente de maneira significativa. 
É importante que o trabalho com o texto literário esteja incorporado às práticas cotidianas da sala de aula, visto tratar-se de uma forma específica de conhecimento. Essa variável de constituição da experiência humana possui propriedades compositivas que devem ser mostradas, discutidas e consideradas quando se trata de ler as diferentes manifestações colocadas sob a rubrica geral do texto literário. (BRASIL,1997, p. 29).

Por conseguinte pode-se por meio desse trabalho verificar que apenas introduzir o texto literário nas práticas diárias não permite um desenvolvimento integral da criança. É necessário que a professora se apaixone pela história antes de contá-las e seja capaz de transmitir a criança. Ainda com Brasil (1997, p. $30)$;

\begin{abstract}
A questão do ensino da literatura ou da leitura literária envolve, portanto, esse exercício de reconhecimento das singularidades e das propriedades compositivas que matizam um tipo particular de escrita. Com isso, é possível afastar uma série de equívocos que costumam estar presentes na escola em relação aos textos literários, ou seja, tratá-los como expedientes para servir ao ensino das boas maneiras, dos hábitos de higiene, dos deveres do cidadão, dos tópicos gramaticais, das receitas desgastadas do "prazer do texto", etc. Postos de forma descontextualizada, tais procedimentos pouco ou nada contribuem para a formação de leitores capazes de reconhecer as sutilezas, as particularidades, os sentidos, a extensão e a profundidade das construções literárias.
\end{abstract}

A entonação da voz assim como a interação entre professor e aluno e o envolvimento emocional de quem conta a história são imprescindíveis. Pois será esse envolvimento o clima de fantasia e o acolhimento com o lúdico que irá despertar na criança o interesse pela história, significar os elementos na sua vivência, assim como também incitar o interesse por literatura e autoria.

Consequentemente os contos de fadas devem ser inseridos de maneira contextualizada, utilizar-se de recursos materiais, e o principal a entonação de voz que é um recurso imprescindível para que o aluno imagine e fantasie gerando possibilidades para o seu desenvolvimento como entendedor, para se tornar um leitor.

\title{
CONCLUSÃO
}

Constatou-se por meio dessa pesquisa que os contos de fadas podem favorecer o desenvolvimento integral da criança atuando no cognitivo, psíquico e sócio-afetivo por meio de situações que permitam exteriorização de sentimentos para significar suas vivências.

Buscou-se por meio dos questionamentos verificar as contribuições da literatura na infância por meio da educação formal.

Observou-se que todos os alunos apresentaram por meio das ilustrações e textos uma problemática ligada à vivência cotidiana e deram, cada um a seu modo, a resolução possível, sempre buscando uma harmonia e o final feliz. Dessa forma, verificou-se que eles exerceram a leitura e a escrita polissêmica, trabalharam o lúdico e ressignificaram a própria realidade. Todos esses dados convergem para uma ligação entre a infância e a literatura, incitando cada vez mais a vontade de ter contatos com textos literários, gerando assim alunos leitores.

Nota-se que ao inserir a literatura infantil na escola, a consequência foi o desenvolvimento tanto da leitura quanto da autoria, pois a literatura apresenta uma linguagem conotativa, polissêmica, plurissignificativa, o que faz com que o aluno leia mais e produza mais. Quanto mais o professor promover ao aluno situações de leitura, maior será a sua devolutiva em termos de construção literária, mesmo que cada um tenha seu próprio tempo. 
Os elementos presentes na literatura infantil, especificadamente nos contos de fadas, contribuem no cenário escolar, para inserir as crianças em um mundo real por meio da ficção, por meio de analogias que facilitam uma inter-relação com suas vivências, ou seja, a literatura utiliza a fantasia para mostrar a realidade.

\section{REFERÊNCIAS}

ABRAMOVICK, F.. Literatura Infantil - Gostosuras e Bobices. $4^{a}$ Ed. São Paulo: Scipione, 1994. 174 p. BETTElHeiM, B.. A psicanálise dos contos de fadas. 28ª Ed. São Paulo: Paz e Terra. 2013. 437 p.

BRASIL. A Especificidade do Texto Literário. In: BRASIL. Parâmetros Curriculares Nacionais. Brasília: MEC/SEF, 1997. 92 p.

CARVALHO, B.V.de. Literatura Infantil: Estudos. São Paulo: Lotus S. A. Editora, [19--]. 382 p.

COELHO, N.N.. Literatura Infantil. 5ª Ed. São Paulo: Ática, 1991. 247 p.

GOMES, C.. Literatura infantil. [s/d]. Disponível em: <http://www.infoescola.com/literatura/literaturainfantil/>. Acesso em: 24 set. 2015.

LAJOLO, M.. O que é literatura. $1^{\text {a }}$ Ed. São Paulo: Brasiliense, 1986. 98 p.

MATTAR, R.R.. Os contos de fadas e suas implicações na infância. 2007. Disponível em: $<$ http://proferlaotrabalhosalunos.pbworks.com/f/TCC++OS+CONTOS+DE+FADAS+E+SUAS+IMPLICAÇÕES.pdf>. Acesso em: 15 jan. 2015.

MEIRA, E.. Contos de Andersen, Grimm e Perrault. Curitiba: Libris, 2011. 233 p.

ROMÃO, L.M.S.; PACÍFICO, S.M.R. . Era uma vez outra história. $1^{\text {a }}$ Ed. São Paulo, Difusão Cultural do Livro, 2006. 104 p.

RIBEIRO, F.. Quem tem medo do lobo mau?. Aventuras na história: Para viajar no tempo. São Paulo: Editora Abril, Ed. 25, p. 54-57, set. 2005.

VIGOTSKI, L. S.. A formação social da mente. $7^{a}$ Ed. São Paulo, Martins Fontes, 2007. 182 p.

ZILBERMAN, R.. Estética da recepção e história da literatura. 1 $^{a}$ Ed. São Paulo, Ática, 2004. 124 p. 